\title{
Unraveling hepatitis C virus structure
}

\author{
Cell Research (2014) 24:385-386. doi:10.1038/cr.2014.31; published online 14 March 2014
}

The high variability and the limited knowledge of the structure of the hepatitis $\mathrm{C}$ virus ( $\mathrm{HCV}$ ) envelope glycoproteins (GP) are challenging hurdles for vaccine design. Recently, Kong et al. published a new model of HCV E2 GP structure in Science, revealing a globular structure, starkly contrasting from the extended model of class II fusion proteins from other Flaviviridae viruses.

Treatment of hepatitis $\mathrm{C}$ virus (HCV)-infected patients has been markedly improved with the development of direct acting antivirals (DAAs) opening a perspective of cure for the majority of patients [1]. However, the high costs and limited access of DAAs in low- or middle-income countries with high $\mathrm{HCV}$ prevalence, the absence of $\mathrm{HCV}$ screening programs, and $\mathrm{HCV}$ re-infection of previously cured patients remain important challenges for the global control of HCV infection. An effective vaccine will undoubtedly be crucial for HCV eradication [2], but its development has been hampered by several factors, most critically the viral evasion of adaptive and innate immune responses [3]. GP E2 is the main target of neutralizing antibodies ( $\mathrm{nAbs}$ ) in $\mathrm{HCV}$-infected patients and a potent immunogen. Although several monoclonal antibodies (mAbs) targeting this protein have been shown to prevent HCV infection in animal models [4], the high variability of $\mathrm{HCV}$ envelope glycoproteins (GPs) enables the virus to efficiently escape nAbs [5].

An important hurdle for the understanding of GP-Ab interactions and vaccine development has been the limited knowledge about GP structure.
For nearly 25 years, researchers tried to solve the E2 structure, but without substantial success. A problematic roadblock was the numerous posttranslational modifications of the GPs such as N-glycosylations and disulfide bridges, which when expressed out of context can form misfolded aggregates. Until now, usage of short E2 peptides in complex with anti-E2 fragment antigen binding regions (FAbs) of nAbs yielded only partial results $[6,7]$. For the first time, Kong et al. [8] by strategically truncating and/or replacing regions of E2, along with co-crystallization with an avidly binding antibody, have succeeded in developing an E2 crystal structure, which in conjunction with negative-stain electron microscopy (EM) gives a novel model of E2. This elegant study renews our concept of the E2 structure, which was anticipated to be extended as in class II fusion proteins from other RNA viruses [9], but instead presents a globular arrangement (key findings summarized in Table 1).

Using different soluble E2 constructs in association with diverse anti-E2 FAbs from a panel of previously characterized human mAbs (HmAbs), Kong et $a l$. succeeded to obtain a well diffracting crystal $(2.65 \AA)$ from an E2 core (E2c) spanning residues 412 to 645 complexed with AR3C FAb. The crystal reveals a general globular shape despite the absence of regular secondary structure. The arrangement of E2c is composed of a central $\beta$ sandwich bordered by two layers (front and back) which are comprised of loops, short helices, and $\beta$ sheets. Despite sequence differences between E2 and E2c, the correct folding of E2c was experimentally confirmed.
Negative-stain EM was next performed using full-length $\mathrm{E} 2$ ectodomain $(\mathrm{E} 2 \Delta \mathrm{TM})$ in association with AR3C FAb. A general shape of the complex E2 $\triangle T M-A R 3 C$ FAb was obtained and $\mathrm{E} 2 \mathrm{c}$ as well as the truncated sites were remapped into this complete structure, confirming the globular structure of E2. Additionally, Kong et al. performed site-directed mutagenesis on E1E2 heterodimer and identified residues of the front layer and the CD81 binding loop as part of the CD81 receptor binding site. Using negative-stain EM, the authors also determined that a dimer of CD81 and $\mathrm{AR} 3 \mathrm{C}$ interacts with the same site on E2. This binding region is globally well conserved and may also contain disordered residues 412 to 420 that are part of the epitope of the efficacious nAbs HCV1 and AP33 [6, 7].

This first successful characterization of E2 structure constitutes a remarkable advance for HCV research and has important implications for the comprehension of virus-host interactions during $\mathrm{HCV}$ entry and viral evasion from neutralizing B cell responses. E1E2mediated HCV attachment and entry is a multistep process essential for initiation, spread, and maintenance of infection. During entry, E2 interacts specifically with different partners including scavenger receptor $\mathrm{B} 1$ and $\mathrm{CD} 81$ as part of a co-receptor complex with claudin-1, followed by fusion between HCV and endosomal membranes, leading to the release of the viral genome in the cytoplasm. This new structure of E2 presented by Kong et al. opens avenues to further characterize E2 interactions with other host factors presumed to bind E2 directly such as heparan sulfates and 
Table 1 Key findings and future implications of the new HCV E2 envelope glycoprotein core structure described by Kong et al. [8]

\begin{tabular}{|c|c|c|c|c|}
\hline $\begin{array}{l}\text { Experiment } \\
\text { objective }\end{array}$ & Tools & $\begin{array}{l}\text { Technique } \\
\text { employed }\end{array}$ & Main results & $\begin{array}{r}\text { Functional relevance } \\
\text { Future implications }\end{array}$ \\
\hline \multirow[t]{3}{*}{$\begin{array}{l}\text { Structural } \\
\text { characterization } \\
\text { of E2 }\end{array}$} & $\begin{array}{l}\mathrm{E} 2 \mathrm{c} \\
\mathrm{AR} 3 \mathrm{C} \mathrm{FAb}\end{array}$ & $\begin{array}{l}\text { X-Ray } \\
\text { crystallography }\end{array}$ & $\begin{array}{l}\text { General globular shape despite irregular secondary structure, } \\
\text { Central } \beta \text { sandwich bordered by two layers (front and back) } \\
\text { comprising loops, short helices and } \beta \text { sheets }\end{array}$ & $\begin{array}{r}\text { Understanding of : HCV morphology } \\
\text { HCV/CD81 interactions } \\
\text { HCV fusion process }\end{array}$ \\
\hline & $\begin{array}{l}\mathrm{E} 2 \Delta \mathrm{TM} \\
\mathrm{AR} 3 \mathrm{C} \mathrm{FAb}\end{array}$ & Negative-stain EM & $\begin{array}{l}\text { Confirmation of E2 globular structure, } \\
\text { Remapping of regions absent in the E2c: }\end{array}$ & \\
\hline & & & $\begin{array}{l}\text { N-terminal region next to the } \beta \text { sandwich } \\
\text { Region } 454-491 \text { at the opposite face of the } \beta \text { sandwich } \\
\text { C-terminal region behind back layer }\end{array}$ & $\begin{array}{l}\text { HCV/host factors interaction research, } \\
\text { Entry inhibitor development, } \\
\text { Immunopreventive strategies, }\end{array}$ \\
\hline \multirow{2}{*}{$\begin{array}{l}\text { Determination of } \\
\text { CD81 receptor } \\
\text { binding site }\end{array}$} & E1E2 heterodimer & $\begin{array}{l}\text { Site-directed } \\
\text { mutagenesis ELISA }\end{array}$ & $\begin{array}{l}\text { Interaction of CD81 with residues of the front layer and the } \\
\text { CD81 binding loop of E2 }\end{array}$ & Vaccine design \\
\hline & $\begin{array}{l}\text { d E2 } \triangle \mathrm{TM} \\
\text { Dimer of CD81 LEL } \\
\text { AR2A FAb }\end{array}$ & Negative-stain EM & A dimer of CD81 and AR3C interacts with the same site on E2 & \\
\hline
\end{tabular}

E2c: aa 412-645, truncations at N- and C- termini, aa 460-485 substituted by a linker, removal of N448 and N576

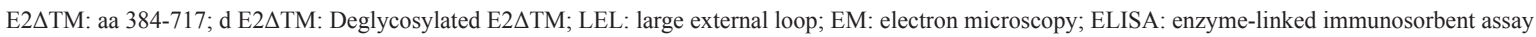

apolipoprotein E. This model also represents a unique tool to better understand the HCV fusion process which remains largely unknown. These future studies will not only allow a better understanding of virus cell entry but also inform therapeutic interventions against $\mathrm{HCV}$ entry, a useful prospect in situations in which DAAs cannot be used or fail due to resistance. Furthermore, nAb responses principally inhibit HCV entry by targeting E2 GP, but E2 sequence variability, numerous $\mathrm{N}$-glycosylations, and viral association with lipoproteins limit the generation of efficacious nAbs [3]. nAb activity might also be disturbed by the presence of interfering antibodies though the mechanism remains controversial. Thus, the approach and conceptual advancement provided by Kong et al. may help to further address the molecular mechanisms of viral escape from nAbs.

Interestingly, the authors characterized a conserved epitope on E2 free of $\mathrm{N}$-glycosylations that critically functions in HCV entry by mediating viral attachment to CD81. The new structural elements of E2 introduced by Kong and colleagues suggest that targeting this epitope could limit viral evasion from nAbs. This region appears as a target of primary interest for preventive strategies, especially immunoprevention of liver graft infection during liver transplantation and vaccine design. This last point is supported by encouraging results obtained in humans using an E1E2-based vaccine that induces neutralizing B cell responses [10], yet even these results were likely limited by poor folding of the recombinant $\mathrm{HCV}$ GP used. Thus, the present study gives new crucial structural information for the use of recombinant E2 protein as part of a preventive vaccine.

It is certain that this study will be the springboard for a series of future enlightening discoveries. The work of Kong and colleagues represents a major step forward in understanding $\mathrm{HCV}$ morphology and provides new perspectives to guide $\mathrm{HCV}$ vaccine development.
Catherine Fauvelle ${ }^{1,2}$, Daniel J Felmlee ${ }^{1,2}$, Thomas F Baumert ${ }^{1,2,3}$

${ }^{1}$ Inserm Unit 1110, Université de Strasbourg, 3 rue Koeberlé, F-67000 Strasbourg, France; ${ }^{2}$ Pôle Hépato-digestif, Université de Strasbourg, Strasbourg, France; ${ }^{3}$ Hôpitaux Universitaires de Strasbourg, Strasbourg, France

Correspondence: Thomas F Baumert

Tel: 33-3 688537 03; Fax: 33-3 68853750

E-mail: Thomas.Baumert@unistra.fr

\section{References}

1 Scheel TK, Rice CM. Nat Med 2013; 19:837-849.

2 Thomas DL. Nat Med 2013; 19:850-858.

3 Liang TJ. Nat Med 2013; 19:869-878.

4 Law M, Maruyama T, Lewis J, et al. Nat Med 2008; 14:25-27.

5 Fafi-Kremer S, Fofana I, Soulier E, et al. $J$ Exp Med 2010; 207:2019-2031.

6 Potter JA, Owsianka AM, Jeffery N, et al. $J$ Virol 2012; 86:12923-12932.

7 Kong L, Giang E, Robbins JB, et al. Proc Natl Acad Sci USA 2012; 109:9499-9504.

8 Kong L, Giang E, Nieusma T, et al. Science 2013; 342:1090-1094.

9 Krey T, d'Alayer J, Kikuti CM, et al. PLoS Pathog 2010; 6:e1000762.

10 Frey SE, Houghton M, Coates S, et al. Vaccine 2010; 28:6367-6373. 